\title{
PRINTER TECHNOLOGIES IN ELECTRONICS. MATERIALS AND DEVICES FOR PRINTING - FIRST RUSSIAN SEMINAR (Moscow, December 15, 2017)
}

\author{
Denis Yu. Kornilov, Sergey V. Tkachev, Evgeny V. Zaytsev, Vitaly P. Kim, Alexey E. \\ Kushnir
}

VNIIalmaz, http://www.vniialmaz.ru, LLC AkKoLab, http://www.akkolab.ru

Moscow 129110, Russian Federation

kornilovdenis@rambler.ru, tkachev_svmsu@mail.ru,gliese3@gmail.com,vp.kim@physics.msu.ru,

kushnir.a.e@gmail.com

Abstract. The review of the reports of the first Russian seminar on problems of printer technologies in electronics and other fields of technology, as well as on materials and devices for printing, is presented. The seminar was held in Moscow by the company "AkKo Lab" LLC in the All-Russian Research Institute of Natural, Synthetic Diamonds and Tools (VNIIAlmaz) on December 15, 2017, under the supervision of Dr Sci Chem, prof. Sergey P. Gubin. 10 reports presented by the seminar participants from Moscow, Zelenograd, Novosibirsk, Tomsk, Saransk and Dormagen (Germany, Nordrhein-Westfalen) were heard and discussed. The reports were distinguished by high level, acute relevance and variety of staging decisions. The work of the seminar is planned to continue.

Keywords: nanoinks based on metal nanoparticles, coordination compounds of metals, carbon nanotubes, graphene and fluorografen, ceramics, inkjet, aerosol and roll printing, microplotter printing, printer electronics, sensors

UDC 004.356.2, 338.27:004

Bibliography - 3 references

Received 16.12.2017

RENSIT, 2017, 9(2):181-204

DOI: $10.17725 /$ rensit.2017.09.181

Contents

1. INTRODUCTION (181)

2. Welcome sPeech by S.P. Gubina (182)

3. Silver, gold and platinum NANO-INK. Production and application (183)

4. SuCCESSES AND PROBLEMS IN THE PRODUCTION OF R2R LARGE-SCALE PRINTED ELECTRONICS (185)

5. Creation of a Cluster of printed ELECTRONICS BASED ON THE CENTER FOR Nanotechnologies aNd Nanomaterials of the Republic of Mordovia (186)

6. Microplotter PRINT OF ELECTRODES FOR ULTRATHIN ORGANIC FIELD EFFECT TRANSISTORS (188)

7. FunCtional INKS BASED ON METAL COORDINATION COMPOUNDS FOR THE CREATION OF THIN-FILM OXIDE NANOSTRUCTURES USING PRINTED TECHNOLOGIES (190)

8. Aerosol CVD synthesis of SingleLAYER CARBON NANOTUBES FOR FLEXIBLE ELECTRONICS (193)

9. Printer technology in electronics (196)
10. 2D PRINTING OF TEST HETEROSTRUCTURES WITH MATERIALS BASED ON GRAPHENE (196)

11. Ceramic "Inks" of low-temperature CURING BASED ON INORGANIC MATERIALS (199)

12. AdDITIVE TECHNOLOGIES FOR GAS SENSORS (200)

13. ConClusion (204)

REFERENCES (204)

\section{INTRODUCTION}

The first Russian seminar on printer technologies in electronics, entitled "Printer technologies in electronics and other fields of technology: Materials and devices for printing" was conceived and initiated by the famous Russian expert on nanochemistry - Professor Sergey P. Gubin, Doctor of Chemistry, laureate of the State Prize of the USSR, Honored Scientist of Russia, Head of the Laboratory of Chemistry of Nanomaterials of the Kurnakov Institute of General and Inorganic Chemistry of Academy of Sciences of Russia. 
Sergey P. Gubin for more than 7 years is the scientific leader of the scientific and production company LLC AkKo Lab, specializing in the development and manufacture of unique innovative materials and energy storage devices based on them - innovative batteries, supercapacitors, ionistors, solar cells, microelectronic devices by inkjet printing with the use of graphene and functional nanoparticles, etc. Years of work in this field in cooperation with many groups of specialists from Russia and abroad caused the demand The possibility of carrying out this work was provided by the VNIIAmaz administration, bearing in mind the 6-year work of the seminar in its graphene conference hall, Moscow, and then the Russian one with international participation [1], whose work was completed in the spring this year.

Representatives of commercial companies, research institutes of the Russian Academy of Sciences and other departments, universities, state funds of Russia and foreign research and commercial centers take part in this seminar, more practical than the seminar "Graphene molecule and 2D crystal". Organizational fee is not provided. Within the framework of the seminar it is planned to hold presentations of participants' works and organize roundtables to discuss various aspects of the current state and future prospects of printer technologies in Russia. The organizers intend to create the conditions necessary for building business contacts for all participants.

Information about the seminar is posted on the website of AkKo Lab LLC http://www. akkolab.ru, and also together with the abstracts of papers and articles on the materials of the seminar in the Russian bilingual peer-reviewed journal "Radioelektronika. Nanosistemy, Informatsionnye Tekhnologii (RENSIT)", which is included in the international abstract databases SCOPUS, EBSCO and Ulrich's Periodicals Directory, DB RINC, RUNEB, RJ and DB VINITI RAS.
More than 40 specialists from Moscow and Novosibirsk, Tomsk and Saransk, Zelenograd and Dormagen (Germany, North RhineWestphalia) took part in the first 7-hour (with a break) meeting of the seminar. Materials received in France and Finland were presented. After the introductory speech of the general director of LLC AkKo Lab, Mark M. Geller, and the welcome speech of the scientific leader of the company Sergey P. Gubin, 10 reports, including the poster materials of AkKo Lab LLC, were heard and actively discussed. The entire course of work was covered by video shooting by the employees of LLC "AkKo Lab" with the posting of materials on the site http://www.rensit.ru.

\section{WELCOME SPEECH. Sergey P. Gubin, Dr Sci Chem, Kurnakov IGIC of RAS, Sci Head of LLC "AkKo Lab", Moscow}

I will be short enough to go directly to the work program. All, apparently, already know and feel that to replace the classical electronics comes post-silicon electronics, soft electronics, electronics on soft carriers, on paper, leather, including. and on human skin, on polymers, on flexible systems of very different origin, on fibers, etc. etc. And all this is based and has arisen not from scratch. The fact is that many researchers for 20 years, or even more, and we, including, engaged in nanoparticles - the basis of nanotechnology, and for the first time on the basis of nanoparticles we created ink, the socalled silver ink 6 years ago. For the first time, the line on the substrate was printed with these inks, heated to a low temperature, and a conductive strip on a polymer base was obtained. It was a long time ago, and now this area, as you all know, is developing very rapidly. And of course the future behind this field of technology, electronics and related fields.

Sometimes they say: Sergei Pavlovich (when I speak in some classrooms), well, you, seriously, what are you saying? This, of course, is more of a mind game, it's more for such scientific interest. Well, who can replace classical electronics 
on silicon and adjacent substrates, in which hundreds of billions of dollars are invested all over the world, which has been developing over the past 50 years, where much has been done, etc., etc., and etc. It's impossible.

In such cases, I usually do not argue. I propose to open the Internet and go to the transport museum, which is in so many cities around the world. In the transport museum you will see on the screen a magnificent photo of one of the last marks of the locomotive. The people sitting in the hall are mostly young people. But there are those who saw these giants in action. I traveled for the first time to Leningrad in the year 1955 on the "Red Arrow" and this train carried locomotive. At that time locomotives were the basis of the movement. It was invested so much efforts, in the world there were dozens of factories. In the year 1955, about 10 thousand locomotives were produced all over the world. And when next to them appeared the first two-carriages electric train Moscow-Mytishchi, gray carriages, some wire up there stretches, it looked very frivolous at the time. Highly. It was hard to believe that the prospect was behind these carriages. Well, now we know - these locomotives are in museums, and where are the electric trains? They speed almost $500 \mathrm{~km}$ per hour in some countries moving in all directions.

The same will be in the area in which we are now working. Undoubtedly, the prospect here is quite obvious, and progress and achievements in this area are inevitable, and we are doing right that all forces are spending their energy on the development of this direction in a variety of ways and in various applications. And in order for this matter to become more intensive, we try to connect it with those who are engaged in science. And here, at the first seminar on this topic, there are representatives of scientific institutions (I myself am also at the main work at the Institute of General and Inorganic Chemistry of the Russian Academy of Sciences) and representatives of different kinds of structures and organizations that work directly with materials on this basis.
There are many problems here and today we will begin this work to unite our efforts, to identify those interesting moments that are associated with the development of this direction

In my short such introduction, I would have remembered only this. I am with a lot of respect for Samsung. For the simple reason that 30 years ago Gennady Borisovich Khomutov and I published some patents and they bought two patents from us. We were still young, inexperienced, hoping that something would come of it. But they quietly bought our patents and put them under the cloth. Since then, there has been no development of this direction. And I love this company, in quotes, so to speak, fell in love, and I always follow its achievements. So last week they reported that they had created a pullover, an ordinary pullover, inside of which there are systems that allow you to accumulate electricity as a result of the activity of the human body, both its heat and its movement, and this electricity is enough to charge your gadget. Any. From this pullover.

This suggests that research and practical developments in this direction are very intensive. Those who follow the literature, knows that now just a boom of work in this direction. And we need to try to find those points, those places where we can be successful in our country and try to develop these directions, come out to the leadership with these or other proposals to support it financially and to ensure that this direction becomes sufficiently significant, if not to say, the key in the development of our branch.

So thank you for attention and turn to our program

\section{SILVER, GOLD AND PLATINUM NANO-INK. PRODUCTION AND} APPLICATION. Kim VP, PhD Phys\&Math., Project Manager of LLC "AkKo Lab", Moscow The company "AkKo Lab" LLC (LLC "AkKo Lab") is a commercial organization that deals with a number of projects, one of which is devoted to printed electronics. The project has 
been developing since 2009, and seems to be the first in Russia. Printing technologies are based on printers (aerosol, inkjet, roll, etc.), functional nanoinks (based on polymers and nanoparticles) and electronic devices and components, printed with printers using nanoinks. Advantages of this technology: the flexibility of electronic devices (electronic circuits on flexible substrates - paper, polymer film, textiles, etc.) and economic benefits (cheaper and faster production). The technology is two-stage: direct printing and low-temperature annealing, in contrast to traditional multi-stage chip manufacturing technologies, which include the high-temperature annealing stage. This allows using in this technology flexible substrates that are sensitive to heat (paper, films, clothing, etc.). This involves many commercial companies, government and research groups. Impressive figures are published on the assessment of market volume and growth rates, it is clear that the quality of products is growing and the number of specializing companies is expanding. Along with laboratory experiments and smallscale production, roll-to-roll printers are now being manufactured that allow the printing of large-scale chips, flexible solar cells, printed circuit boards, etc. on a large scale. Now these are hundreds of companies, in which the employees of "AkKo Lab" were convinced, participating in the next exhibition Printed Electronics Europe 2017, held May 10-11 in Berlin. The exhibition was visited by more than 3500 participants, more than 225 companies presented their developments in the field of printer electronics.

The company"AkKoLab" has developed several types of nanoinks based on metallic nanoparticles - gold, platinum and silver (Fig. 1). To such inks printer manufacturers make very high and specific requirements. There are a number of parameters that need to be maintained in order to use the ink in
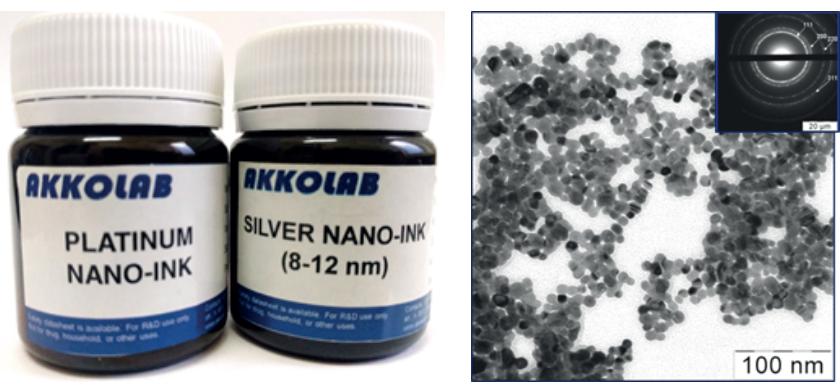

Fig. 1. Nanochernila company "AkKo Lab." the printing of electronic components, in particular, particle concentration, their size, size dispersion, surface tension, viscosity, etc. So if massive silver melts at a temperature of more than $900^{\circ} \mathrm{C}$, silver particles with dimensions of about 10 nanometers begin to cake at $100^{\circ} \mathrm{C}$, which allows to obtain conductive structures on substrates that degrade at temperatures above $100^{\circ} \mathrm{C}$. In 2015 , the ink of the company "AkKo Lab" successfully confirmed its quality in the research center of Fujifilm Dimatix, Inc. (Santa Clara, California, USA), one of the largest printer manufacturers. According to the results of these studies, the company "AkKo Lab" is included in the recommendation list of FujifilmDimatix, Inc. which consists of 12 companies, available online to all owners of FujifilmDimatix printers. "AkKo Lab" is the only company from Russia that passed these test tests. In the list you can see manufacturers of nanoinks from the USA, France, Japan, etc. In general, manufacturers and developers of ink in the world is quite a lot, which is caused by high competition. However, not everyone can demonstrate the quality of the product. After the inclusion of "AkKo Lab" in this recommendatory list, we have orders, mainly from abroad (England, France, Spain, South Korea, etc.). In turn, in Russia, this is devoted to research works carried out by individual scientific groups in universities and commercial structures. In order to increase the sales volume and show the practical suitability of the product, we cooperate with many companies and institutions. The result of such $R \& D$ is the printed working electronic devices (Fig. 2, 3), and to bring it to mass production is already the next level that is in Russia at the initial stage. Thus, "AkKo Lab" today is a company that has already established

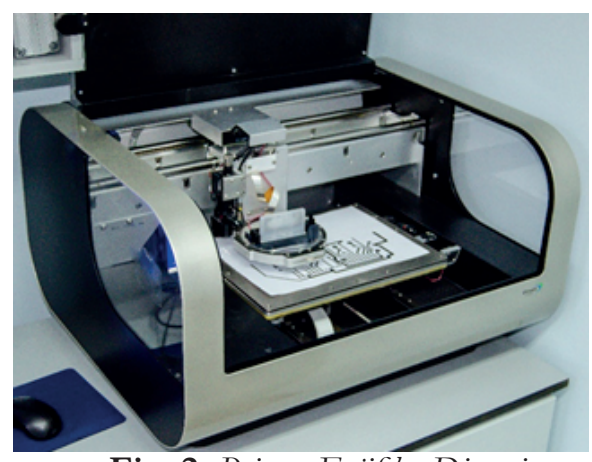

Fig. 2. Printer Fujifilm Dimatix. 


\section{NANOSYSTEMS}
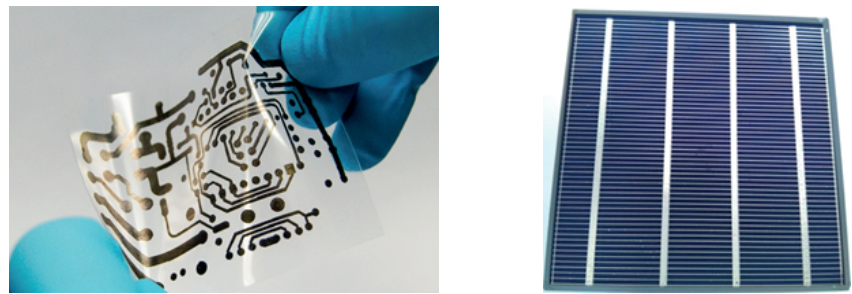

Fig. 3. Printed samples of conductive structures on a transparent film and a solar battery.

a small-scale production and implementation of nanoinks, has confirmed their quality at the highest level and can currently produce nanoinks in volume up to a liter a month. This is not such a large volume, which is in demand in the market. Now the demand is growing, it is necessary to keep up with it and present the appropriate quality of the product. Moreover, in order for the Russian company to take place on the foreign market, it is necessary to cover our activities. On the Internet, the dynamics of news in this area can be monitored on the portal of Printed Electronics World (https:/ / www.printedelectronicsworld.com) - the source of global news on printed, organic and flexible electronics. Where we also publish the results of our experimental work. Today, printer technologies are an interesting, rapidly developing and, I'm sure, profitable area.

\section{RECENT PROGRESS AND CHALLENGES IN R2R MANUFACTURING OF LARGE AREA PRINTED ELECTRONICS.}

Busch Martin, Dr.-Ing., Business Development Manager "Coatema Coating Machinery GmbH" (Dormagen, Germany)

For 40 years Coatema Coating Machinery $\mathrm{GmbH}$ has been designing and constructing coating and laminating equipment for fabrics, carpets, artificial leather, etc. Most substrates
PRINTER TECHNOLOGIES IN ELECTRONICS. 18 MATERIAL AND DEVICES FOR PRINTING - FIRST...

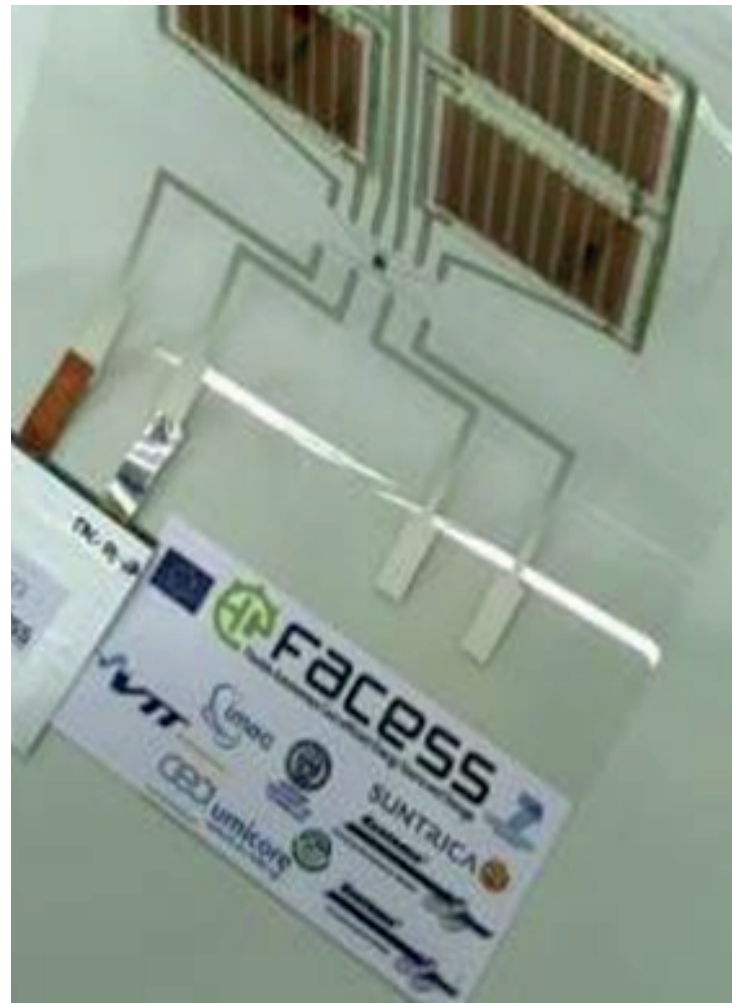

Fig. 4. Flexible autonomous cost efficient energy source and storage. and chemicals can be treated with Coatema equipment either in sheet form or from rolls. Approximately since 2003, Coatema focuses on new markets, now a third of our equipment - for the production of printed electronics. Coatema equipment develops and manufactures advanced flexible electronic technologies, such as OLED lamps and signboards, organic sensors, smart packaging, OLED displays, optical coatings, RFID applications and flexible printing processes. There is a large equipment for this. First we produced small coatings, searched for suitable chemistry, viscosity and other parameters on small machines, the smallest shaft-on-shaft machine by $500 \mathrm{~mm}$, then more, now - the

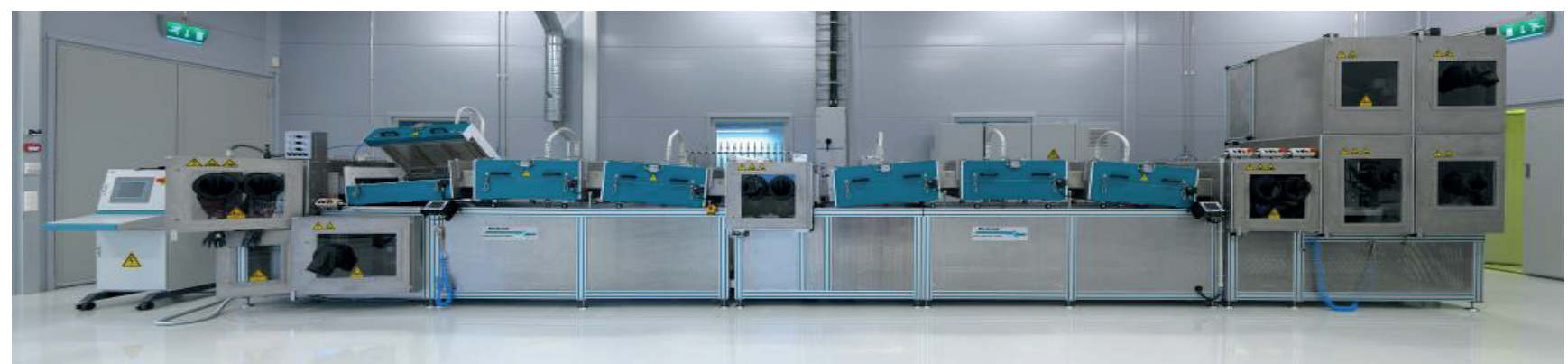

Fig. 5. R2R in nitrogen environment 


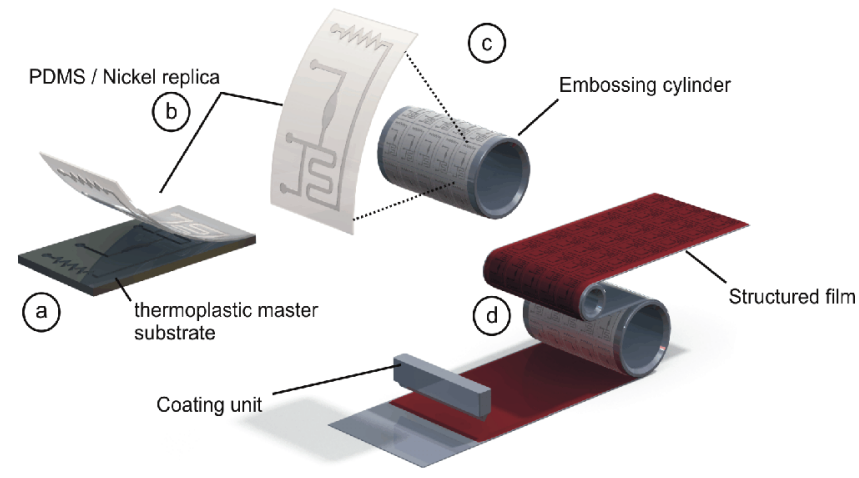

Fig. 6. Nanoimprinting system.

largest line in Europe, on which a $55 \mathrm{~m}$ long substrate is produced.

To solve the problems, there are more than 30 different spray systems and systems for printing. The most interesting system for encapsulation, which protects electronics and ink from water, oxygen and other gases. It is used not only for protection, but also as a function, when it is necessary to have a very even layer of electrolyte on a large scale. With a low viscosity, it is difficult to obtain an even and good surface. A mask is used in which the ink lies where necessary. Last year, a new scheme was applied, usually this is one unit, which has a hole that allows to make minimal movements when applying ink. This works about 2 milliseconds, very quickly, which is not an easy task for production. Other systems, for very small structures (micrometers) are slow, for large structures can be faster, the system is very dense and flexible, because the costs for a single substrate are the same as for a macroprint. New systems that use microstructures or nanostructures allow printing up to 50-70 nm. Earlier it could be realized only with the use of vacuum systems. Now we dispense with this and with a roll press. The liquid polymer is applied to the film substrate, the structure is printed in the microand nanometer mode, at the same time here it is dried by ultraviolet and then separated from the shaft. This structure is already in a solid state. This gives great opportunities for different systems, for example, for displays
- more light, for photovoltaic it absorbs better, for nutrient media - bacteria can not grow well, because structure hinders.

The firm invites to itself to Germany if not to buy cars, then to try on them the systems.

\section{CREATION OF A CLUSTER OF PRINTED ELECTRONICS ON THE BASIS OF THE CENTER FOR NANOTECHNOLOGIES AND NANOMATERIALS OF THE REPUBLIC OF MORDOVIA. Krakhin D.N., Dir. of Center for Nanotechnologies and Nanomaterials of the Republic of Mordovia, Saransk.}

The topic of the report is not so much printer technology, as the organization of business on these technologies. Our experience shows that this business is promising.

Nanocentre of the Republic of Mordovia is a joint venture between Rusnano and the Republic of Mordovia, i.e. Rusnano with their source - the budget, and the republic, and the center invests this money in the company that it creates. The center is part of the venturebuilding network of nanocenters, which is organized by the structures of Rusnano. For today, there are 15 nanocenter in Russia, which annually from scratch, create 150-200 start-ups, and the result of this work for a few years now in Russia created about 900 technological start-ups, this is half of all operating start-ups in Russia. We work in the technical sphere, we do not deal with IT, it's the business of Rusnano.

Nanocenter as a whole is a business to create a business, the nanocenter tries to serially create companies for subsequent sale and make it faster and cheaper than is customary. Throughout the world, start-up technology companies are developing from scratch to success for about 20 years. We are trying to reduce this period to 10 years due to the fact that we add a certain component of seriality and by investing in the infrastructure of the chosen specialization.

Nanocentre of Mordovia has chosen for itself the following specialization - power electronics, 
new materials, modern lighting technology, devices. For 5 years of operation, the nanocenter created about 50 startups with different specializations, and printing technologies in this portfolio occupy a key role.

The choice of this industry - printing technology, happened by chance. Several years ago Saransk visited the Finnish company VTT (Oulu) for the production of light-emitting technologies. We managed to conclude a transfer agreement with her on this part of the technology, we invested a corresponding start-up, which for today promotes the serial production of a light-emitting film produced by a roll method, its conductive tracks are printed on a polymer substrate, LEDs are mounted and we get some super- which is used with such a form factor, where before the advent of such technology it was impossible to use light. An example is a windshield of a bus where the film is laminated inside the glass and can be a full-fledged display for indicating route information. Today it is a pilot project of the world's leading glass manufacturer. Other applications are possible that allow the integration of light-emitting elements into building materials, wallpaper-like materials, textile elements, etc. To date, this is one of the few examples of the use of printed technology. A joint center in collaboration with the Finns has been created to improve this technology and develop practical aspects of its application.

A research center for printed electronics is being created, focusing on sheet printing and the creation of hybrid electronics. Defined several key tasks. First and foremost application applications through the creation of start-ups, in close communication with different partners, in order to obtain up-todate information about where this industry is heading. It is planned to work not only on applied things, but also with materials, arranging some kind of vertical integration of this direction, in the future we will scale our activities, because in the laboratory scale it is impossible to conduct business.

A laboratory equipped with the most upto-date equipment for printed electronics was created (Fig. 7): these are the preparation facilities for substrates, printers, equipment for drying the material, analytical equipment, a glovebox for working in an inert environment, everything necessary to work in this direction. The created team is already working on the selection of materials, development of printing methods, the creation of components, some integrated devices for the use of printed methods. The company has implemented several custommade $R \& D$, for example, methods have been developed for manufacturing a laminating film for low-temperature sintering for a large power electronics plant in Saransk, radio frequency modification methods for one of the Rusnano project companies, etc.

To date, the world is serious about replacing silicon chips with plastic materials with radio frequency modification. On such a plastic chip we apply a printed UHF RFID antenna based on an electroconductive paste of our own production (working range - UHF, reading range $3 \mathrm{~m}$ ), in a single technological cycle a label is made and printed on the product package. Now this is a general trend, when in the production of a product such a label is sewn up to carry out tracking of products throughout its life cycle.

Another one of our product is stretchable

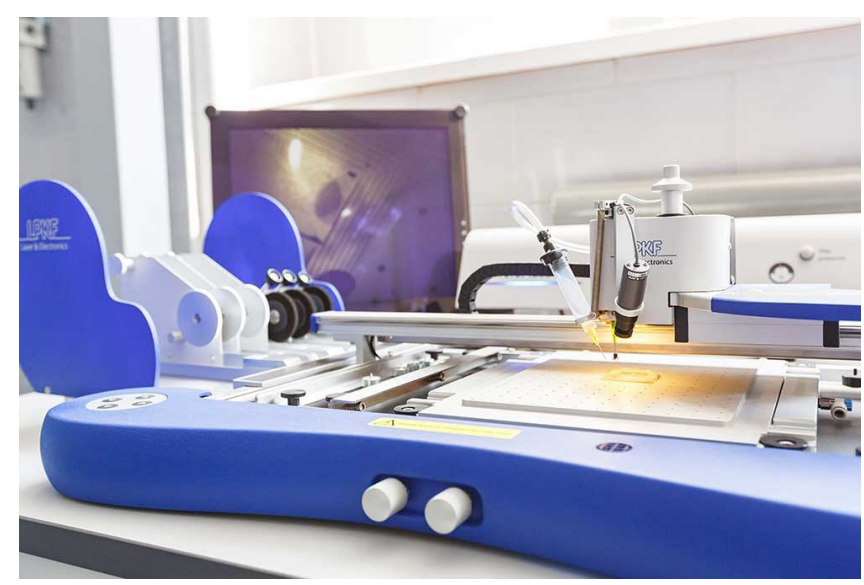

Fig. 7. Laboratory of printed electronics. 


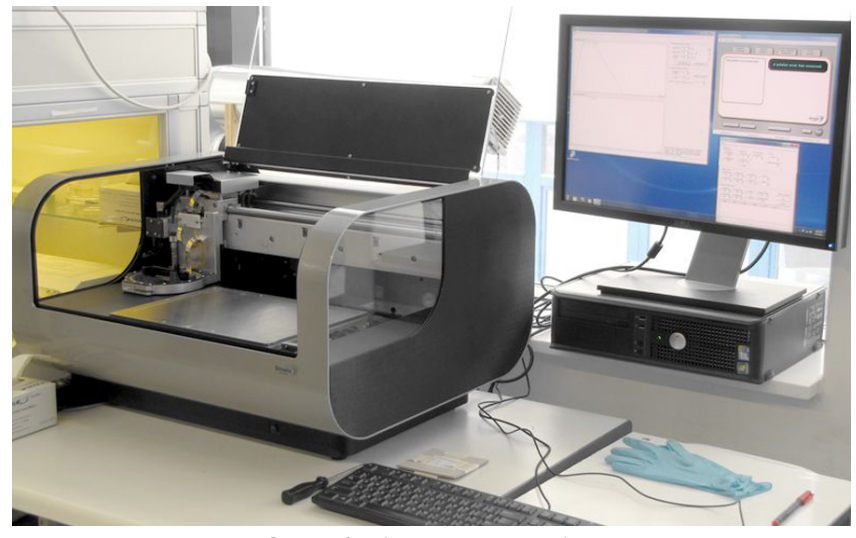

Fig. 8. Stretched current-conducting paste.

electrically conductive pastes (Fig. 8). For clothing, it is important that the ink that provides current carrying is in the elements that stretch. It was possible to develop a stretchable paste, which is not inferior to the international analogs declared in open sources, but we are still making a substantial reduction in the cost of this paste due to the introduction of metals in addition to silver. For example, copper, coated with silver the cost of the paste fell by $20-30 \%$.

In 2016, our company TC "Printing Technologies" became a member of the Finnish industrial cluster PrintoCent, which includes more than 40 companies from around the world - dozens of startups, SME companies such as ASUS GROUP, LSE companies such as Nokia, BASF, etc. Such clusters include not only research and development centers, there are large businesses that form today's request for the technology of printed electronics for its subsequent introduction into their products. Companies such as the manufacturer of sheet equipment Konen, the glass company Pilkington, the Finnish manufacturer of wearable electronics are companies with multimillion-dollar turnovers, plus those stratapes that produce certain series around this infrastructure.

Startup is a product company that forms its product based on market requirements, potential consumers. One example - the startup PrintoSense solves the problem of bringing to the market modern print sensors for various applications. The company has established a small-scale production of sensors: biosensors, capacitive sensors, piezoresistive and piezoelectric, optical, temperature and humidity sensors, gas

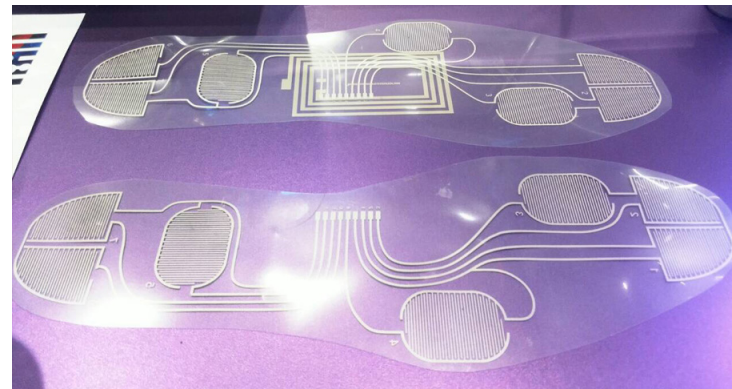

Fig. 9. Insoles for shoes with built-in pressure sensors.

sensors, pressure sensors. There is a whole catalog of sensors that are widely used in the same automobile industry - tire pressure, measuring the fit of the windshield wiper against the glass, the density of the doors, as well as various examples of ergonomic applications, such as chairs, where you need to measure the degree of depression. Bending sensors - measuring the degree of bending of elements in robotics, fitness, sports equipment, orthopedics, restorative medicine, in the gaming industry. Startup SmartStep - manufacture of insoles for sports, for medical rehabilitation (Fig. 9). Flexible LED RGB screen, displays on the basis of transparent, thin films used in windows, which do not yet serve as an advertising element, provide light transmission from the outside, and outside can carry information for stores, service centers, including decorative.

We are now at the very beginning of the journey, we have created a laboratory, a certain system of start-ups and partners. Next year, we plan to invest in contract production, semiindustrial, for 1-10 thousand pieces of products. In the future, we need to scale up to full-fledged production, so that those startups with whom we work can serially produce these products. Thus, this message shows the cluster and its components with the prospect of creating an industrial structure with developed cooperation.

\section{MICROPLOTTER PRINT OF ELECTRODES FOR ULTRATHIN} ORGANIC FIELD-EFFECT TRANSISTORS. Parashchuk DYu, Dr Sci Phys\&Math, Prof., Physics Faculty, Lomonosov Moscow State University, International Laser Center of MSU. Organic electronics is a booming branch. At the Physics Faculty of the Lomonosov Moscow 
State University there is the laboratory of organic electronics (Chair of General Physics and Wave Processes), mostly young people, there is an annual school in the Moscow region, the 4th school on organic electronics has already passed.

In organic electronics, low cost, flexibility, and transparency are attracted. In terms of speed, organic electronics is far from silicon. You can do not fast computers, but lighting devices, sensors, sensors, batteries (solar), etc. Another problem is instability of organic matter.

The problem of forming an organic transistor is solved on a silicon substrate no more than a centimeter, we clean it, we check the surface, we introduce the transistors with a microplotter. An organic transistor is a device about three electrodes, has an active layer, and two drainsource electrodes that form an ohmic contact. The third electrode is a branch, it is separated by an insulator, with the help of a voltage on the gate it is possible to change the conductivity of an organic conductor. This is the basis of all devices. The carrier layer has a size of the order of one molecule $(1 \mathrm{~nm})$, where the charge carriers move in contact with the dielectric. The main characteristic of such a device is the mobility of a charge carrier of tens of $\mathrm{cm}$ per square inch, amorphous silicon is about 1 . Such transistors can already be comparable or better than amorphous silicon transistors that are used on all liquid crystal screens.

When we print the electrodes, we need from ink in addition to their viscosity-type parameters, etc., the work function for these inks. It is determined by the metal that is there, and its size. Because when it comes to semiconductor devices, we need to ensure the injection of electrons into either the valence band or the conduction band of electrons. Therefore, you need to have metals with different work functions. And not like gold (in gold ink) about $5 \mathrm{eV}$, but much lower and much higher. For all light-emitting devices, it is necessary to ensure the injection of electrons and holes, so that the electron is at the level of $3 \mathrm{eV}$, and the hole is $5 \mathrm{eV}$, then luminescence will appear and the energy of the transition will go to light.

We are working on ultrathin organic transistors of a molecule-wide thickness and the production of electron and hole conductivity by liquid-phase methods. Transistors with such conductivity allow creating a light-emitting device. Substances such as teraphene phenylene oligomers with ten alkyl substituents, and other substances with electron and hole conductivity or only with hole conductivity were used. At this stage, only hole conductivity was investigated. As the semiconductor layer, ultrathin crystals obtained by annealing in solvent vapors were used. Growth of the semiconductor layer in the solvent vapor (quite a new direction): a solution with a concentration of $0.11-0.23 \mathrm{~g} / 1$ is applied to the cleaned substrate, the substrate is centrifuged, unwound at a speed of 200-1000 $\mathrm{rpm}$ (the parameter varies), then the substrate is placed in a closed atmosphere in a Petri dish) for 4 hours at room temperature, is closed, where crystal growth occurs. Using a concentration of $0.13 \mathrm{~g} / \mathrm{l}$ provides for the production of thin crystals of large area. X-ray diffraction analysis showed that the oligomer used gives a monolayer single crystal of very large dimensions.

Then, using liquid-phase methods, electrodes are applied to these layers. We use the method of plotter microprinting on a silicon substrate. The microplotter (GIX Mocroplotter Desktop (SonoPlot), Fig. 10) is equipped with a 3D

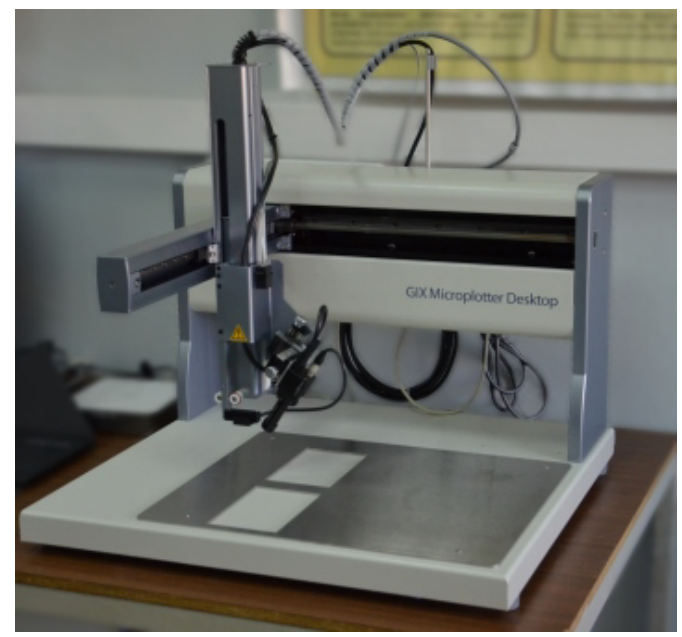

Fig. 10. The microplotter GIX Mocroplotter Desketop (SonoPlot) 
positioner with a precision of 20 microns for accurate application of liquid substances (points, continuous lines, arcs) as electronics components. Equipped with a piezoelectric dispenser (a minimum volume of 1.8 picles, a viscosity of not more than $450 \mathrm{cPs}$ ) for noncontact drawing of a pattern with a minimum element size of 30 microns. Equipped with a digital video camer.

As the ink used PEDOT:PSS, mixed with dimethyl sulfoxide, which increases the conductivity of the electrodes. Water is usually added. To reduce the work function, a surfactant was sometimes added to closely adhere the electrode to the crystal. But the surfactant destroys the contact area of the crystal and then was not used in the manufacture of transistors. Printing technology - drip or solid. Drip application to the right and left of the crystal creates a semiconductor channel, but the drop destroys contact with the crystal, being carried away by the capillary. Solid print - the capillary moves along the surface of the substrate.

After drying, the transistors are scratched out (so that there is no leakage of charge), separated from each other, using a micropinette or a special probe under a microscope and placed in an argon atmosphere. We get an organic semiconductor transistor and examine its characteristics.

Characteristics of transistors based on an ultra-thin crystal DD-5T (Table 1). The current volt-ampere curves show that the obtained values of the transfer characteristics in the saturated mode (Vsat $=-50 \mathrm{~B}$ ) and the output characteristics are not high, but in such a thin crystal at low currents the current density is very high, besides these substances have luminescent properties. I.e. it is possible to combine the properties of conductivity and luminescence.

Table 1

Characteristics of transistors based on an ultra-thin crystal DD-5T.

\begin{tabular}{|c|c|c|c|c|}
\hline \multicolumn{3}{|c|}{ Saturated Mode } & \multicolumn{3}{c|}{ Linear Mode } \\
\hline$\mu_{\text {sat }}, \mathrm{sm}^{2} / \mathrm{Vs}$ & $\mathrm{V}_{\text {Tsat }}, \mathrm{B}$ & $\mathrm{I}_{\text {on }} I_{\text {off }}$ & $\mu_{\text {lin }}, \mathrm{sm}^{2} / \mathrm{Vs}$ & $\mathrm{V}_{\text {Tlin }}, \mathrm{B}$ \\
\hline $0.310 \pm 0.015$ & +28 & 7500 & $0.25 \pm 0.013$ & +26 \\
\hline
\end{tabular}

Advantages. 1. High characteristics of devices: on these substances with the help of other methods, higher characteristics were not obtained. 2. Ease of use: do not use vacuum methods to printing electrodes. 3. The devices do not degrade over time (which is not always possible with organic electrodes): the mobility does not change for 3-4 months.

Disadvantages - it is not always possible to form a semiconductor channel, you may need to use other inks.

So, in our work, optimal "ink" was selected for printing electrodes. Using printed methods, transistors with high hole conductivity were obtained on the basis of ultrathin crystals.

Requires "ink" for electrodes for efficient injection into wide-band organic semiconductors with an output function of $5.5-6 \mathrm{eV}$ for holes and $4 \mathrm{eV}$ for electrons, so that recombination of electrons and holes can occur with the release of a quantum of light.

\section{FUNCTIONAL INKS BASED ON METAL COORDINATION COMPOUNDS FOR THE CREATION OF THIN-FILM OXIDE NANOSTRUCTURES USING PRINTED TECHNOLOGIES. Simonenko NP, PhD Techn., Kurnakov IGIC RAS, Moscow}

Thin-film structures are in demand when creating transistors, receptor layers in sensorics, detectors of various gases, solar batteries, energy storage devices, transparent electrodes and various optical devices. The technology for the production of functional ink is also rapidly growing in interest in the technologies for creating thin-film structures based on them. The main methods for obtaining thin films are chemical CVD and physical PVD deposition of the gas phase, dip-coating, spin-coating and, more recently, called additive technologies. Additive Manufacturing (3D printing, layered synthesis): stereolithography, fusing, selective laser sintering, laser sintering of metal, 3D printing, lamination, inkjet printing with polymers and inkjet printing with ink. As the most popular is such additive technology as 
inkjet printing inks. As the ink are a variety of liquid media - dispersions, solutions of different viscosities, etc. We in our work in cooperation with AkKo Lab and MIPT used such printing devices to create various thin film structures like the Dimatix DMP-2831 inkjet printer and the Sonoplot GIX Microplotter II microplotter. There are a lot of devices for printing, printing technologies are actively developing, but in order to create structures of complex chemical composition, a problem arises in functional inks. These inks, in addition to what is lacking, must still be subject to rheological requirements, and etc. properties. When printing dispersions of nanoparticles, as is known, there are big problems, this is the effect of a "coffee stain", when the solid phase of the ink is distributed unevenly over the substrate and some structures are formed. This process is difficult to control, it is difficult to predict the electrophysical and other functional properties of the resulting materials. In addition, the use of nanoparticles results in clogging of printheads with nanoparticles, there is a need to suppress sedimentation of particles and stabilize these dispersions and sufficiently stringent requirements for the particle sizes that are components of these inks.

As a functional ink, we propose to use not the dispersions of nanoparticles (without detracting from their merits), but the true solutions of the coordination compounds of metals with the specified composition of the coordination sphere. These solutions (in organic solvents), in connection with what are true, immediately eliminate some of the disadvantages of the dispersions. There is no big problem associated with sedimentation of particles, the effect of the "coffee stain" is suppressed, the process of clogging of the printheads is eliminated. Thus, using these solutions, it is possible to apply thin films on different substrates. At the first stage we apply a film of a solution based on heteroligand metal complexes. Due to the processes of polycondensation, hydrolysis, a cross-linking occurs, a polymeric coating is formed in the form of a polymer network. The next step is the crystallization under various influences temperatures, optical effects, etc. At the same time, a crystalline oxide coating is formed whose properties - thickness, roughness, porosity - depend on the properties of the initial components, which are coordination compounds with a given reactivity. We obtain coordination compounds of the given chemical composition, we study the coordination environment, the degree of screening of the central atoms affects the rheological properties of the functional inks obtained. In particular, the dependence of the rheological properties of ink solutions on the composition of the coordination sphere is given as an example. As can be seen, the degree of replacement of one ligand by another ligand by several percent leads to a change in the kinetics, a change in rheological properties by an order of magnitude. That one can use and control the processes of structuring, self-assembly on a substrate. As an example, we obtained a thin film of nickel oxide. The temperature dependence shows that in the range from room temperature to about $200^{\circ} \mathrm{C}$, the electrical resistance decreases by 3 orders of magnitude. In addition, it is shown that the thickness of the film significantly affects the electrophysical properties. In particular, if the number of layers increases by a factor of 2 , then the resistance can be reduced by several times.

On the example of manganese dioxide, a similar experiment was conducted: a xerogel film was applied to the specialized sensor using manganese coordination compounds. The film was subjected to a stepwise heat treatment. The temperature dependence of the electrical resistivity shows that in the course of this treatment the process of crystallization of manganese oxide proceeded and the resistance in the temperature range 


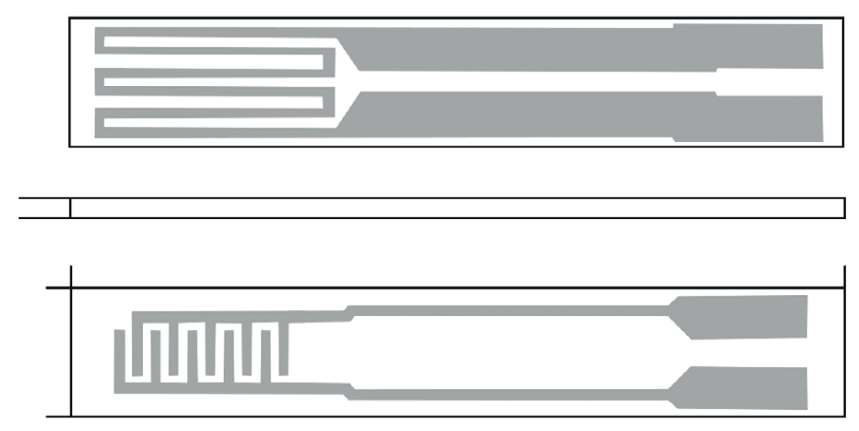

Fig. 11. Scheme of the sensor; white color - $\mathrm{Al}_{2} \mathrm{O}_{3}$-ceramic, gray - Pt-electrodes and microheater.

from room temperature to $200^{\circ} \mathrm{C}$ decreases by 3 orders of magnitude or more.

In cooperation with AkKo Lab, we printed with our inks - titanium oxide doped with zirconium $\mathrm{TiO}_{2}-\mathrm{ZrO}_{2}$ was applied by three layers of functional ink $(10 \mathrm{~mol} \%)$ to the region of the interdigital probe electrodes (Fig. 11, bottom, left) by high-resolution inkjet printing method. A polymer film was formed, with subsequent heat treatment, titanium oxide doped with zirconium crystallized. The film is very thin, not individually fixed. With the help of Raman spectroscopy it has been shown that it does exist. The microstructure was studied by scanning electron microscopy. It is seen that this film is a grid consisting of particles of about 10$20 \mathrm{~nm}$ in size, arranged in a certain way. It should be noted that there are also defects in the size of hundreds of $\mathrm{nm}$, sometimes microns. They are caused primarily by the heterogeneity of the substrate, in this case, its roughness of tens of micrometers. This is critical for such thin films, therefore the quality of the substrate determines further functional properties. It was shown that the size of one pixel of a given composition of titanium oxide doped with zirconium is approximately $35 \mu \mathrm{m}$, the structure is obtained using a Dimatix printer.

The obtained film of titanium oxide with zirconium was studied for the fact of detection of various gases. It has been shown that when using it as a component of resistive sensors, the concentration of oxygen can be detected in a wide range: the resistance of the film increases with increasing contact with oxygen, this response increases with decreasing operating temperature of the sensor. It is also shown that the stability of this response during playback is high enough.

With the help of a microplotter, the processes of printing thin-film structures were also studied. In particular, in cooperation with MIPT, structures of various shapes, including concentric circles of manganese and in the form of a grid, were obtained on glass substrates. Quartz and silicon substrates also produced concentric circles of $\mathrm{CeO}_{2}-\mathrm{ZrO}_{2}$, with a line width in the range of 100-200 $\mu \mathrm{m}$ approximately. Thin-film structures of cerium oxide composition were obtained on alumina substrates. It was shown that the speed of moving the needle of the microplotter significantly affects the microstructure of the film systems, and with increasing the displacement of the needle from $1 \mathrm{~mm} / \mathrm{s}$ to 5 it can be seen that the structures are uneven.

It has also been shown that the ink created on the basis of coordination compounds can be used in hand-held type printers of the type of markers into which these inks can be poured and manually create some thin-film structures, in particular, a line width of about $500 \mu \mathrm{m}$ was obtained.

Thus, as a result of our work, a technology was developed to produce functional inks based on metal coordination compounds to create thin-film nanostructures of complex chemical composition using high-resolution printing technology. It is shown that the obtained thin oxide films can be used as receptor components of resistive gas sensors and in other applications, depending on their chemical composition.

\section{AEROSOL CVD SYNTHESIS OF SINGLE- WALLED CARBON NANOTUBES FOR FLEXIBLE ELECTRONICS. Albert G. Nasibulin, Dr Sci Techn, Prof. of the Skolkovo Institute of Science and Technology, Moscow} While in Finland, at the Helsinki Aalto University, where I worked for 16 years, we developed a method for producing single-walled carbon nanotubes (SWNTs) in the gas phase, an aerosol CVD method for their synthesis [2]. I will explain 
my method using the example of the ferrocene vapor $\mathrm{FeC}_{10} \mathrm{H}_{10}$ decomposition method (Fig. 12). Ferrocene is an organometallic compound, quite volatile at room temperature and at a pressure of 8 pascals, blowing carbon monoxide, which in this case plays two roles: a carrier gas and a carbon source for the growth of nanotubes. Carbon monoxide passes through the cartridge, which is filled with ferrocene powder, saturated with vapors, and then the vapor-gas mixture enters the water-cooled pipe directly into the hot reactor with a temperature of about $1000^{\circ} \mathrm{C}$. In it, ferrocene decomposes, as a result - catalytic iron nanoparticles are formed and on the surface we have the decomposition of carbon monoxide, as a result - the release of atomic carbon, which is necessary for the growth of carbon nanotubes. The vapor-gas mixture, the entire flow in the reactor is about 12-15 seconds, during this time it is necessary to control all the growth processes. At the output, the nanotubes collect on the filter. It is removed from any substrate (silicon, glass, flexible lavsan, etc.), a polymer film, usually in advance, for better adhesion, rubbed with alcohol or acetonitrile. And as a rule, with the addition of gold chloride - to simultaneously dope the resulting network of nanotubes, which increases

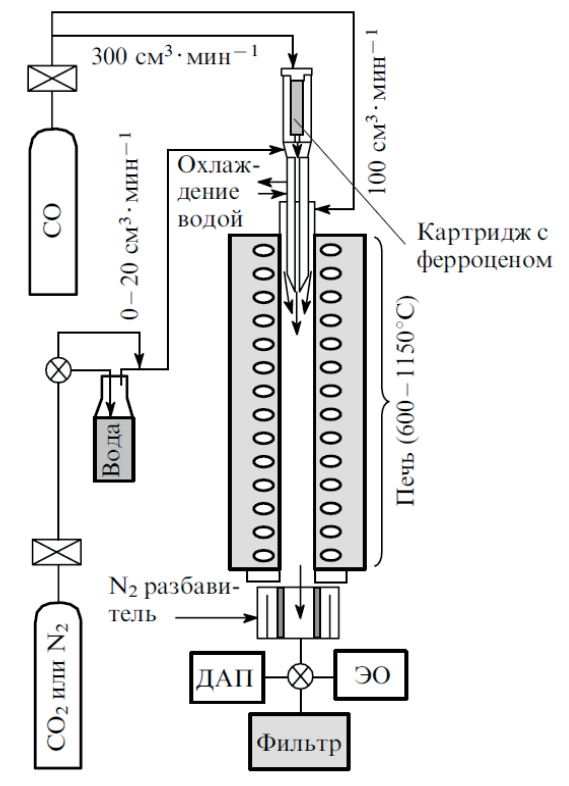

Fig. 12. Aerosol method for the synthesis of single-walled carbon nanotubes (DAP - differential mobility analyzer, EO - electrostatic precipitator) their conductivity by $5-10$ times. The film of tubes on the substrate sits tightly, it is not possible to tear off the usual scotch tape. It is planned to measure adhesion due to van der Waals forces between the substrate and nanotubes in numbers with a device that the cat has just bought. With a filter, nanotubes go off easily, because the filter is made in the form of fibers and contact with the tubes is very small. When we push the substrate, these connections arise.

Single-layer carbon nanotubes form a rather high quality randomly oriented networks nanotubes $(1-2.5 \mathrm{~nm})$, which is confirmed by the Raman spectra (Fig. 13a): the presence of a radial
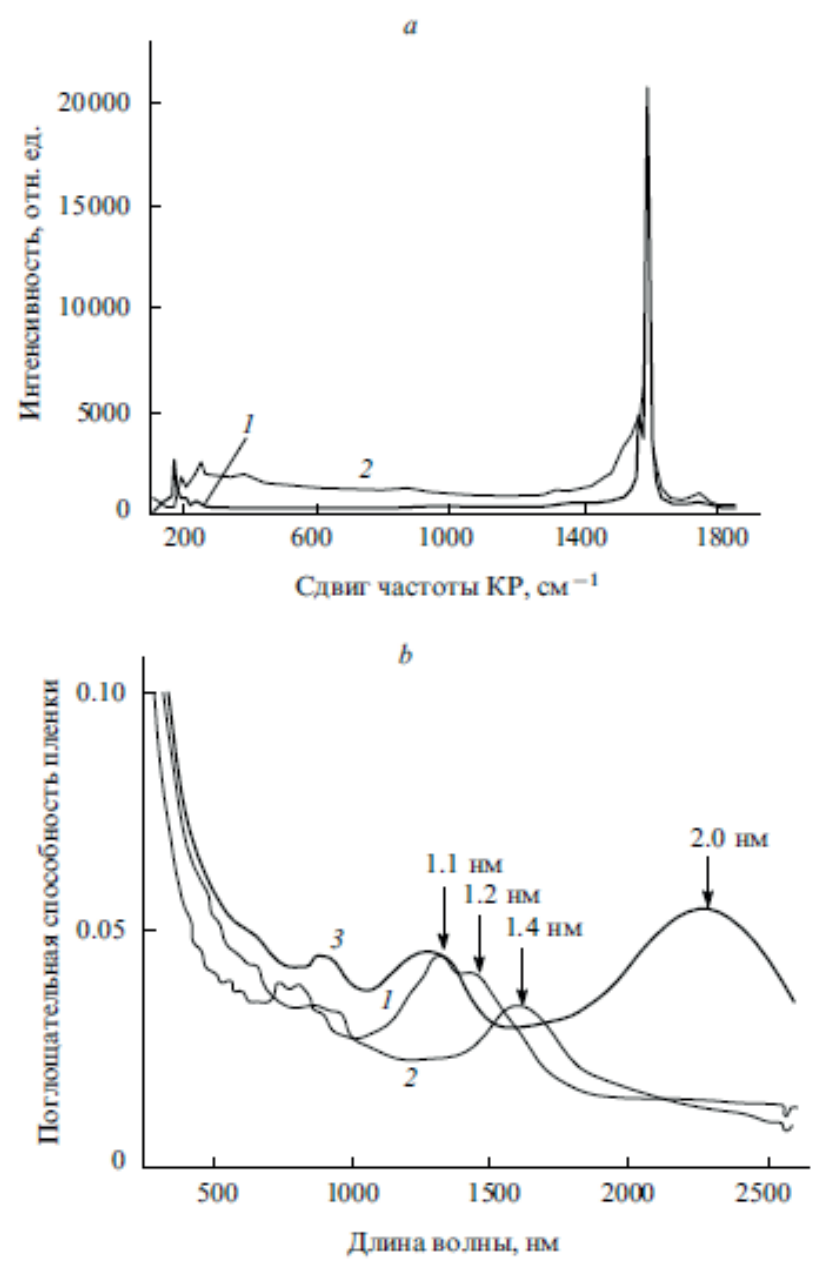

Fig. 13. Results of research of SWCNT synthesized in the process of the ferrocene decomposition: a - Raman spectra for excitation wavelengths 488 (1) and $633 \mathrm{~nm}$ (2), b absorption spectra of SWCNTs synthesized with various additions of carbon dioxide $(1-0,2-0.5 \%, 3-1.0 \%)$ and a temperature of $890^{\circ} \mathrm{C}$. The arrows indicate the mean diameters of SWCNTS calculated for electronic transitions between the first $V$ an Hove singularities. 
respiratory mode (RDM) at low frequencies $\left(100-200 \mathrm{~cm}^{-1}\right)$ in Raman spectra indicates the presence of SWCNTs. A special feature of the spectra is a strong Auger band (with a peak at $1592 \mathrm{~cm}^{-1}$ ) and a low $D$-band intensity (about $1300 \mathrm{~cm}^{-1}$ ), indicating a small fraction of the disordered carbon in the synthesis products. Fig. $11 \mathrm{~b}$ - optical absorption spectra of SWCNT at different concentrations of carbon dioxide, the peaks correspond to electron transitions in nanotubes. By changing the concentration of carbon dioxide in the reactor, it is possible to significantly change the diameter of nanotubes, in fact covering the entire spectrum from ultraviolet to near infrared.

A method for preparing electrodes is proposed - dry printing, after the reactor, dry transfer of SWCNT from the filter to any substrate, including elastic one. The size of the filter is now brought to the A3 format. If you make special flow limiters under the filter, you can achieve the formation of patterns from nanotubes with a resolution of about 30 microns. In this case, the requirements for the materials of the substrates: all production takes place at room temperature $\left(<100^{\circ} \mathrm{C}\right)$, since polymers do not withstand high temperatures. In addition, one of the requirements is low pressure, it is desirable that the whole process occur at atmospheric pressure, with high speed, and should also be compatible with roll printing. The substrate materials currently used, such as silicon and transparent conductive oxides (ITO, $\mathrm{ZnO}, \mathrm{Cd}_{2} \mathrm{SnO}_{4}, \ldots$ ) can not be used. We need alternative materials. A classic example is indium tin oxide (ITO), which is used in 75\% of electronic devices as a conductive top layer applied to the polymer. If it is bent, it breaks at a low angle of bending. While the carbon nanotubes on the plastic in the fatigue test at a radius of $1 \mathrm{~mm}$ flexion withstand about 30,000 bending cycles before the degradation of electrical conductivity.

On the other hand, if we are talking about transparent films, it is necessary to mention their surface resistance. Now with ITO, doped with tin on a flexible substrate, it is possible to obtain about $40 \mathrm{ohm}$ per square with a transparency of $90 \%$.

About the work connected with AkKo Lab: we bought graphene oxide from it, dispersed it, applied it to the surface of nanotubes, obtained a hybrid material, reconstituted at atmospheric pressure and temperature of $300^{\circ} \mathrm{C}$, dripped gold chloride $\mathrm{AuCl}_{3}$ and obtained a good conductivity of $34 \mathrm{ohms}$ per square at $80 \%$ transparency.

Our nanotubes can also be used to create thin-film field-effect transistors. So in 2011 on polycrystalline silicon received a ratio of currents of $10^{6}$, in 2013 , mobility and charge mobility surpassed $10^{7}$.

In addition, our material can be used to create organic light-emitting diodes (OLEDs) and capacitive touch sensors. The first sensor of 2010, our company together with Nokia introduced these nanotubes into mobile phones, cars that contain touch sensors made of singlewalled carbon nanotubes by our technology are already being sold.

In addition, our films can be used in solar batteries, on organic dyes, on heterojunctions, when we put carbon nanotubes on the $n$-type silicon, we are doping $p$-type, and thus obtain a $p-n$ junction on crystalline silicon of the order of $14 \%$. On amorphous silicon while $2.7 \%$.

Another one of our project is elastic electronics. We had an ambitious goal to combine flexible, transparent and elastic electronics into one component. Carbon nanotubes applied to the elastomer can withstand tens of thousands of tensile tests. On the other hand, these same carbon nanotubes can be used as motion detectors, if applied to a carbon nanotube, which in principle can not be done with metals. Carbon nanotubes, films with stretching occupy the most favorable energy position and when stretched twice the resistance of the material changes by only $1 \%$. The reason for this stability: conducted an in situ study inside an atomic electron microscope to see what happens to nanotubes when stretched. 
With a $20-40 \%$ stretch, the nanotubes become oriented along the stretch. When we were stretched by $55 \%$ and released, wrinkles formed, which ensure the unchangeability of the electrical resistance during stretching. In operation with elastic supercapacitors, the capacitance was not high, but at $120 \%$ stretching the characteristics of the supercapacitor do not practically change. That is, it is proved that this material is suitable for high-elastic electronics.

In cooperation with the Lomonosov Moscow State University, work was done to create a loudspeaker made from SWCNT. Here, the SWCNT film is in a freely suspended state, there is no substrate. An example is a SWCNT film $1.0 \times 1.0 \mathrm{~cm}^{2}$, a thickness of $20 \mathrm{~nm}$, a resistance of 110 ohms, a distance to a microphone of $3 \mathrm{~cm}$. In conventional loudspeakers, there are membranes that push air, in this case nanotubes do not move, the sound is produced by the fact that the film is very quickly heats up and cools - so called thermoacoustic effect. Now we check whether it is possible to use such films for something useful. It turned out that such a film generates an ultrasound up to $100 \mathrm{kHz}$ and a comparison with the literature data shows that this film exceeds the available analogues in its characteristics.

In cooperation with Novosibirsk State University, work was done on the use of the SWCNT film as an IR photodetector (so-called bolometer): a quartz substrate was coated with a hybrid film, gold electrodes for detecting a change in the resistance of the film with heating; this detector is faster than industrial samples in terms of its speed. If you want to force the film to absorb in a narrow IR range, you need to perforate half the film and thus you can force the film to absorb in a certain narrow spectral range.

In addition, our nanotubes can be used as saturable absorbers. A cheap Chinese laser, Erfiber, was used, a small number of tubes were applied to the tip of this fiber, about $30 \mathrm{ng}$ is sufficient, and depending on the conditions of use, nanosecond and subpicosecond pulses can be recorded.

Another project - an electronic "nose" based on nanotube networks, the task of digitizing the smell, make this device not only highly sensitive, but also highly selective.

From CNT, which we synthesize by the aerosol method, it is possible to obtain not only a film, but also fibers. It is possible to pull fibers with a diameter of about $20 \mu \mathrm{m}$ with good mechanical and electrical properties that can be used for many applications - as current collectors in solar cells.

Thus, the aerosol method of synthesizing thin-walled CNTs and preparing transparent electrodes are promising methods for their commercialization in future flexible and elastic electronics. Features of the technology: room temperature, vacuum-free technology, simple and fast process, cheap. The goal is to create a large and low-cost production component for flexible and transparent electronics using R2R roll technology.

\section{PRINTER TECHNOLOGY IN ELECTRONICS. Isaykin A.V., Dir. LLC TC "Printing Technologies", Saransk.}

Core technology to create printed electronics: Chemical Bath, Spin-coating, Dip-coating, Doctor Blade, Metering Rod, Slot-casting, Spray-coating, Screen Printing, InkJet Printing, Aerosol Jet. There are two markets - the materials market and the equipment market. Our company positions itself as a developer of both printing methods and new materials. Analyzing the relevant literature, we chose the key development factor - the development of stretchable electronics. The base is conductive elastic composites, which have a wide range of applications, mainly in portable electronics. We have concentrated on the development and analysis of commercial products that can cover this niche. At the moment, there are only a limited number of such elastic compositions that have high resistance and stretchability. Often additive methods are used, such as the 
use of lamination of textiles, double lamination, the application of conventional polymer phases and post lamination, but these are not exactly elastic composites. After a series of tests, we have developed a composition: elastomer (high stretchability) and conductive filler electroconductive paste, the characteristics superior to the existing analogues, based on copper, coated with silver (electrodeposition of $\mathrm{Cu}$ in the $\mathrm{AgNO}_{3}$ solution) to reduce the amount of silver in the final product and, accordingly, of the cost by $20-30 \%$. The paste impregnates the fabric due to the capillary effect, silver penetrates inside, envelops the fibers of the fabric, not over the surface, as in lamination. When stretching almost 2 times, the conductivity naturally falls, but remains high enough. Another feature of the approach is the use of reactive additives, MOD-precursors (carboxylic acids), functional additives. In the course of the thermal action, as a result of thermal destruction, they generate in situ particles, both micro- and silver nanoparticles. The dispersity of silver nanoparticles is quite high. We use the principle of coating hybridization, filling with various pastes, to obtain layered structures. The composition was successful, together with the Lobachevsky University (Nizhny Novgorod), INGsystems are created, the seal fits into them.

In addition, the company is developing a project with thin-film surfactants. The main problem of electrically conductive pastes is an increased electrical resistance compared to conventional conductors. To solve it, the following approach is applied. A polymer surfactant ( $60 \pm 2 \%$ by weight) was added to the paste. Drying of printing layers is carried out at an elevated temperature of $120^{\circ} \mathrm{C}$ with the formation of silver nanoparticles in situ, which substantially increases the conductivity. The electrical resistance of the printed layers was reduced by $20-25 \%$ without deterioration of adhesion, resistance to weathering and flexibility. This correlates with the world data.
10. 2D PRINTING OF TEST HETEROSTRUCTURES WITH MATERIALS BASED ON GRAPHENE. Irina V. Antonova, Dr Sci Phys\&Math, Senior Researcher Rzhanov Institute of Semiconductor Physics of SB RAS (Novosibirsk).

Within the framework of the RNF 15-12-00008, within 3 years, work was carried out in a new area for us - the creation of graphene suspensions and liquid compositions for $2 \mathrm{D}$ printing from graphenebased materials. All approaches known from the literature were studied and a method for obtaining particles by electrochemical stratification of graphite and subsequent treatment with a dispersant (particle thickness 1-3 nm, lateral size 1-5 $\mu \mathrm{m}$ ) or ultrasound was selected, breaking them down to smaller particles and obtaining a high yield of single- , two and three-layer particles (Fig. 14). Electrochemical stratification of graphite usually produces slightly oxidized (20-30\%) graphene, the use of which allows to significantly reduce the annealing temperature $\left(300^{\circ} \mathrm{C}\right)$ to restore conductivity. The problem of the stability of suspensions and ink after recycling a number of organic solvents was solved in favor of aqueous solutions.

The films and structures were fabricated using a two-dimensional printing method on a Dimatix Fujifilm DMP-2831 printer equipped with a DMC11610 print head with 16 nozzle carriers of about $20 \mu \mathrm{m}$ in diameter. Ink - with particles less than $400 \mathrm{~nm}$. The printing process was realized both on solid and on flexible substrates. The solid substrates
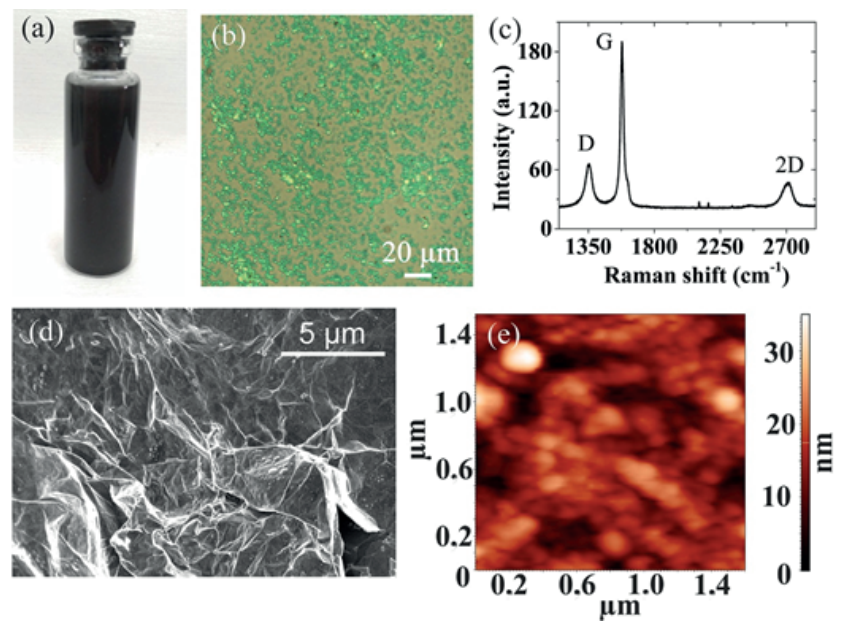

Fig. 14. (a) graphene suspension, (b) optical image of graphene flakes, (c) Raman spectrum of 2-3 nm thick suspension particles, (d and e) SEM and AFM images of films prepared from the graphene suspension. 
were silica $\mathrm{SiO}_{2} / \mathrm{Si}$ with an oxide thickness of $300 \mathrm{~nm}$, coated with APTES (3-Aminopropyl) threeethoxysilane film to ensure good adhesion of the water-based ink. Flexible substrates are polyethylene terephthalate (PET) substrates with an adhesive coating (Lamond), Epson inkjet printers and polyamide films (Kapton).

Resistance of layers of graphene ink: layer $>200$ $\mathrm{nm}-200 \mathrm{ohm} / \mathrm{sq}, 20-40 \mathrm{~nm}-1-3 \mathrm{kOhm} / \mathrm{sq}, 3 \mathrm{~nm}$ - $16 \mathrm{mOhm} / \mathrm{sq}$. The main work - on films from 1 to $30 \mathrm{~nm}$, droplets of the order of $3 \mathrm{~nm}$ had a resistance of the order of megOhms. The maximum mobility of $100 \mathrm{~cm}^{2} /$ Vs was observed in films of monolayer or bilayer particles of the order of $1 \mathrm{~nm}$ on a $\mathrm{SiO}^{2} / \mathrm{Si}$ substrate. As the particle size increases, the mobility decreases sharply. When PEDOT:PSS was added to improve the liquid composition, the mobility decreased during printing and over time the resistance changed much more than when printing simply with graphene.

The second material we use is fluorographene (FG), which is obtained by fluorinating a suspension of graphene in an aqueous solution of hydrofluoric acid. With strong fluorination, we obtain particles with a lateral dimension of $20-50 \mathrm{~nm}$ and a thickness of up to $2 \mathrm{~nm}$. Suspensions are absolutely transparent, when printing a film (without surfactant), the surface relief is about $2 \mathrm{~nm}$ with a roughness of $0.3 \mathrm{~nm}$. Transparency of films at thicknesses of about $20 \mathrm{~nm}$ is $97-98 \%$ in the visible range. The low-point leakage $\left(<10^{-4} \mathrm{~A} / \mathrm{cm}^{2}\right)$, ultralow charge in a film and on a heterointerface with Si, GsAs, InAs: $\mathrm{Q}=(1-4) 10^{10} \mathrm{~cm}^{-2}$ are measured on the MIS structures on a silicon substrate (FG and contacts) (droplets) $\mathrm{Q}=(0.5-2) 10^{10} \mathrm{~cm}^{-2}$ (film). Such small charges in other materials are unknown.

Another type of suspension that we use is a suspension of G-NMP (graphene in nitromethylpyrrolidone). However, for very small graphene particles, the conductivity of this suspension is absent. We obtain dielectric films with small leakage currents, with photoluminescence from different layers. There are no applications for this suspension yet.

Fluorographene on flexible substrates has good characteristics (leakage currents, breakdown voltage, etc.) and is very promising as a dielectric film for electronics.
A construction of metal-FG-metal (silver suspension $+F G$ ) was printed on paper: the number of printed layers is $10-20$, the film thickness is $8-16 \mathrm{~nm}$, the leakage current is $10^{-8} \mathrm{~A} / \mathrm{cm}^{2}$, the breakdown voltage is $10^{7} \mathrm{~V} / \mathrm{cm}$.

Hybrid transistor structure: a multigraphene film $(2 \mathrm{~nm})$ transferred to a printed FG layer or encapsulated FG. The mobility of electrons has increased several times, for holes has not changed. If the FG film was applied to a flexible substrate, CVD graphene was transferred to it and above it was encapsulated FG, the conductivity of graphene increased 5-6 times.

Graphene oxide (OG). The technology of its production is developed, but if used it as a dielectric layer, it is very unstable. Correction of the properties of such OG layers by printing from the top of a thin layer (2-4 nm) of fluorographene, with graphene oxide having a complex relief and no continuous FG layer; however, its stability increased significantly and the leakage currents of FG/GO 0.2-0.02 mA/ $\mathrm{cm}^{2}$, those. The leakage currents fell by an order of magnitude (Fig. 15).

The production of material for memristors is a two-layer structure of FG/PVA. On a porous matrix of polyvinyl alcohol PVA, a thin film of FG with a metallic contact is printed. On the current-voltage characteristic, go to the open
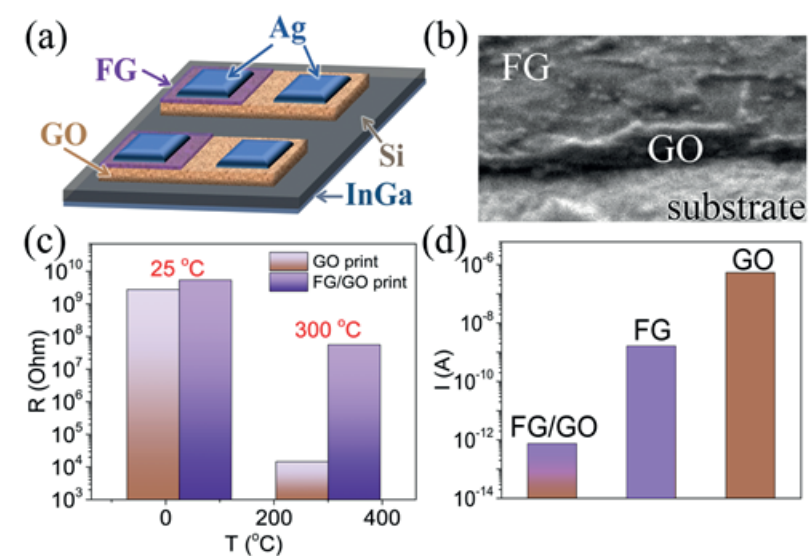

(d)

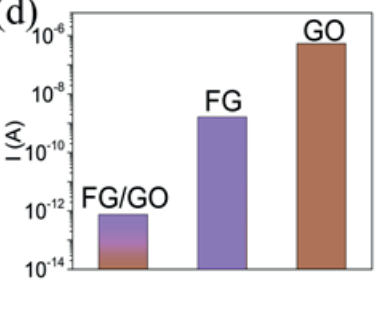

Fig. 15. (a) Test MIS structures with gate dielectrics formed from FG/GO and GO films. (b) SEM image of the two-layer film. (c) Histograms of resistance values in the MIS structures with the $F G / G O$ and GO films before and after an annealing performed at $300^{\circ} \mathrm{C}$ during 30 min in argon ambient. (d) Histograms of leakage currents across the FG/GO bilayer films, and histograms of leakage currents across the component GO and FG films in the structure. 
state, remove the voltage, wait for 4 hours and continue recording - the open state remains, i.e. as an element of memory it works.

The most interesting result obtained by us is the observation of the resistive effect on a composite of FG with vanadium nanoparticles $\mathrm{V}_{2} \mathrm{O}_{5}$. The $\mathrm{Ag} / \mathrm{Fg}+\mathrm{V}_{2} \mathrm{O}_{5} / \mathrm{Ag}$ structure on the flexible substrate exhibited a stable resistive switching effect of $\sim 5-8$ orders of magnitude for the $\mathrm{FG}+\mathrm{V}_{2} \mathrm{O}_{5}$ transverse structures with Ag contacts.

Fully printed transistor - printed channel, shutter, metal contacts: substrate - polyimide film, channel from weakly oxidized graphene + annealing $300^{\circ} \mathrm{C} 30 \mathrm{~min}-9 \mathrm{k} \Omega /$ square, gate insulator $-\mathrm{OG}+\mathrm{FG}$, carrier mobility $1-0.2 \mathrm{~cm}^{2} / \mathrm{Vs}$, contacts - silver paste $2 \mathrm{ohms} /$ square for a thickness of $400 \mathrm{~nm}$. As a transistor it turned out nothing, the mobility is very small, for bending $-4 \%$ at a bending radius of $5 \mathrm{~mm}$. So far - such a beginning.

Graphene dipole antenna at $1.8 \mathrm{GHz}$. The relief of the edge of the antenna does not exceed $50 \mu \mathrm{m}$, the layer resistance of the graphite layer is $8-20 \Omega / \mathrm{sq}$. The second antenna - 4-6 Ohm/square.

Thus, [3], several variants of suspensions of graphene and slightly oxidized graphene for the formation of conductive layers fluorographene with different degrees of fluorination, and a suspension of graphene functionalized with $\mathrm{N}$-methylpyrrolidone for the production of dielectric layers have been developed. To obtain fluorographene suspensions, a simple and technological fluorination method was developed for the treatment of graphene in an aqueous hydrofluoric acid solution. A Russian patent was obtained and numerous evidence of the fluorination process was obtained. Investigation of the properties of the obtained fluorographene showed that in the case of a relatively low degree of fluorination, a system of quantum dots of graphene embedded in the fluorographene matrix is formed, and the layers obtained from such a slurry exhibit a negative differential resistance on the current-voltage characteristics, which expands the range of their possible applications. With a greater degree of fluorination of the suspension, films having unique properties of dielectric materials (gate dielectrics, insulating coatings, etc.) are obtained. From the developed suspensions, test instrument structures such as transistors, MIS structures, memristors, capacitors, etc. were printed and investigated.

The main participants of the work are the PhD Med. N.A. Nebogatikova, engineer I.A. Kotin, the leading chemical engineer R.A. Soots, and post-graduate students A.I. Ivanov and E.A. Yakimchuk. Also involved in the project were employees of the laboratory "Graphene Nanotechnologies" of the North-Eastern Federal University named after M.K. Ammosov in the city of Yakutsk under the direction of PhD Phys\&Math S.A. Smagulova.

\section{CERAMIC "INKS" OF LOW-} TEMPERATURE CURING BASED ON INORGANIC MATERIALS. Ivanov A.A., PhD Chem; Tuev V.I., Dr Sci Techn., Dir. Research Institute of LED Technologies of Tomsk State University of Control Systems and Radioelectronics, Tomsk.

In the report with this name, we are not talking about ceramics, but about filled polymers with properties close to ceramic materials. The term "ink" on a serious level is, apparently, used incorrectly. Classes of materials-ink, creating conductive structures, tracks - silver, platinum, copper, as well as materials that create semiconductor structures - polythiophenes, fluorenes and others. To complete the functional range, only dielectric materials - polymethylmethacrylate and others - are missing. But with dielectrics it's not so simple. And the point here is in the solutions of engineering problems, with the removal of heat from semiconductor structures. It is known that the lifetime of reliable semiconductors depends to a large extent on the temperature regime of operation. If at $60^{\circ} \mathrm{C}$ you can predict 
the 50,000th service life of the devices, then at $125^{\circ} \mathrm{C}$ this lifetime decreases in multiples, and at $150^{\circ} \mathrm{C}$ you can leave only a limited number of hours or tens of minutes. Therefore, the problem of heat removal during the implementation of engineering solutions is the number one task. Even with the advent of semiconductor light-emitting diodes, this task only worsened. Calculations show that compared to a 40-watt incandescent bulb having an area of $100 \mathrm{~cm}^{2}$, a 1-watt LED crystal with an area of $1 \mathrm{~mm}^{2}$ requires a substantially higher density of heat dissipation.

I will present some results on the production of materials that can be used in the liquid phase, in the form of ink, for their technological application, with obtaining parameters for thermal conductivity, electrical strength, close to ceramic materials. Ceramics is a sintering material at $1800^{\circ} \mathrm{C}$, lowtemperature ceramics, widely used in recent times, is $800-1200^{\circ} \mathrm{C}$, and the materials I will talk about are $200^{\circ} \mathrm{C}$, i.e. this is super-super low-temperature ceramics. The aim of the work was to obtain a material that could be applied with printing technologies and the result of application of which would allow obtaining films with parameters approximating to the parameters of ceramic materials.

As far as the filled polymers are concerned, it is not a secret that polyaluminosilicate is used as a binder here, which, under certain mechanical and chemical treatments, allows to include a relatively large amount of powder that determines the final properties of this product. In the present work, aluminum hydroxide was used. The limitations imposed here are that the film is created on a metal base, on aluminum. Aluminum is chosen here not only because it is light and cosmic material, but based on the chemical affinity of the materials used to create the dielectric layer, and in particular, for this reason, it seems to us that relatively good parameters for the adhesive strength of the films have been obtained. The application technologies used in the pilot studies, two are screen printing and aerosol printing. The production of ceramic coatings on aluminum surfaces by aerosol printing of the obtained ceramic material was carried out on a Neotech AMT 3D printer of Aerosol Jet 15EX brand, located in OOO NIIIT of OSTEK-Group company in Moscow.

Practically obtained experimentally confirmed technical parameters of dielectric films on a metallic, aluminum base (Table 1). The above values of the breakdown voltage, strangely enough, lay on a straight, linear dependence, which in our opinion indicates a high repeatability of deposition of films of different thicknesses. The total value of $U_{b r}$ of the obtained insulation coating is $14 \pm 0.55 \mathrm{kV} /$ $\mathrm{mm}$.

The value of $U_{b r}$ of the sample of the insulation coating $(14 \mathrm{kV} / \mathrm{mm})$ is less than the values of $U_{b r}$ of the samples of normal $\mathrm{Al}_{2} \mathrm{O}_{3}$ and AlN ceramics (15.3 and 17.3, respectively). When forming (by screen printing, TP) a layer on a rough aluminum surface with a thickness of more than $100 \mathrm{~mm}$ and subsequent lowtemperature drying in air at $25^{\circ} \mathrm{C}$, during the polycondensation of the polymer matrix, free condensation water forms nanoscale pores and some structural defects that can be seen in photographs cross-section. That causes a smaller value of $U_{\text {br }}$ of the sample of insulation coatings compared to UPR of $\mathrm{Al}_{2} \mathrm{O}_{3}$ and $\mathrm{AlN}$ samples, sintered by hot pressing.

Finally, thermal conductivity is the most important parameter for engineering applications. The numerical values of the various powders

Table 1

Electrical strength of insulation coatings

\begin{tabular}{|c|c|}
\hline Thickness, $\mathrm{mm}$ & Breakdown voltage $\mathrm{U}_{\mathrm{br}}, \mathrm{V}$ \\
\hline $73 \pm 0.7$ & $1022 \pm 31$ \\
\hline $54 \pm 0.5$ & $756 \pm 23$ \\
\hline $53 \pm 0.5$ & $742 \pm 22$ \\
\hline $40 \pm 0.4$ & $560 \pm 17$ \\
\hline $27 \pm 0.2$ & $378 \pm 11$ \\
\hline $19 \pm 0.2$ & $266 \pm 8$ \\
\hline
\end{tabular}


Thermal conductivity of insulation coating

\begin{tabular}{|c|c|}
\hline Thickness, $\mathrm{mm}$ & Coefficient, $\mathrm{W} / \mathrm{m} \cdot \mathrm{K}$ \\
\hline $73 \pm 0.7$ & $18.7 \pm 1.7$ \\
\hline $54 \pm 0.5$ & $24.6 \pm 2.4$ \\
\hline $53 \pm 0.5$ & $26.7 \pm 2.6$ \\
\hline $40 \pm 0.4$ & $30.2 \pm 2.9$ \\
\hline $27 \pm 0.2$ & $33.9 \pm 3.3$ \\
\hline $19 \pm 0.2$ & $46.5 \pm 4.5$ \\
\hline
\end{tabular}

obtained in the study are given in Table 2 . The average thermal conductivity of the coating is $30 \pm 2.9 \mathrm{~W} / \mathrm{m} \cdot \mathrm{K}$ with an average coating thickness of $44 \pm 0.4 \mu \mathrm{m}$. Such a developed material, when used, when designing the electronic component of the base (semiconductor diode housings, complete blocks) allows to provide an acceptable thermal mode of operation of semiconductor devices and operational parameters of the devices being developed.

Experimental results of testing the adhesive strength of the insulation coating have also been obtained. Characteristic curves after a scratch test of a sample of an insulating coating on an aluminum base show that up to 30 Newton per meter is not observed tearing off the material, i.e. accordingly, acoustic emission does not begin and, indirectly, the numerical value of this parameter indicates good adhesion strength of the dielectric coating on the aluminum substrate.

Thus, two important parameters of the dielectric coating have been experimentally confirmed in the values of breakdown voltage and thermal conductivity.

This work was partially supported by the Ministry of Industry and Trade of the Russian Federation..

\section{ADDITIVE TECHNOLOGIES FOR} GAS SENSORS. ${ }^{1,2}$ Alexey A. Vasilyev, Dr Sci Techn; ${ }^{3}$ Nisan AV, ${ }^{3}$ Potapov GN, ${ }^{1}$ Pislyakov A, ${ }^{3}$ Shakhnovich I, ${ }^{4}$ Samotayev NN, ${ }^{5}$ Tkachev SV, ${ }^{5} \mathrm{Kim}$ VP.

${ }^{1}$ NRC "Kurchatov Institute", Moscow; ${ }^{2}$ MFTI, Dolgoprudny, MO; ${ }^{3}$ RIIT LLC OSTEK enterprise, Moscow, Rusia; ${ }^{4}$ NYAU MEPhI, Moscow; ${ }^{5}$ AkKo Lab, LLC.
The printer print of gas sensors is one of the applications of printing technologies, in which the use of high resolution is important. This resolution is possible in such printing technologies as inkjet and aerosol printing. As is known, there are a number of gas sensors: electrochemical, optical (NDIR-non-dispersive infra-red), piezo (microbalance), semiconductor, thermochemical (thermocatalytic), optoacoustic and thermal conductivity. Our subject is semiconductor and thermocatalytic gas sensors.

We have long been working in gas analysis, with gas sensors, semiconductor and thermocatalytic sensors. Their feature is work at a sufficiently high temperature. They use a catalyst, which oxidizes gas-reducing agents with oxygen in the air. And that this chemical reaction proceeds quickly enough, the sensitive layer, semiconducting or simply catalytic, needs to be heated from a temperature of up to $200^{\circ} \mathrm{C}$ to detect hydrogen from alcohol, to a temperature of $450^{\circ} \mathrm{C}$ to oxidize a difficult-oxidizing methane molecule.

The technologies used to make such thermocatalytic and semiconductor sensors:

- Volume ceramic technology, the old one, has practically disappeared;

- Wire microcoil for thermocatalytic and semiconductor gas sensors;

- Screen printing - transfer of ink through holes in the printed form;

- Silicon micromachining - silicon microprocessing;

- and finally, what we are now trying to introduce into practice is the technology of ceramic microelectromechanical systems (MEMS).

A modern thermocatalytic sensor used in mines to determine the methane concentration (0.1-10 vol.\%) is a small spiral (100 microns in diameter) made of vitrified platinum wire 10 microns in diameter, this spiral is covered with a layer of $\mathrm{Al}_{2} \mathrm{O}_{3}$ catalyst (about $100 \mathrm{~m}^{2} / \mathrm{g}$ ), doped with platinum and palladium. At an operating temperature of 
$450^{\circ} \mathrm{C}$, such an element consumes about 60 milliwatts; usually a pair of such elements is used - one coated with a catalyst, the other is not. Then the power is in the region of 120-150 milliwatts, in general, a little, but for devices that would like to be used in wireless conditions, networks, cell phones, this power is a bit too much.

We are the only manufacturer in Russia of semiconductor gas sensors manufactured using screen printing technology. The minimum size of the element that can be obtained using this technology is approximately $2.5 \times 0.3 \times 0.1 \mathrm{~mm}$. It is suspended on a $10 \mathrm{~mm}$ holder using 10 -micron platinum wires. To get a temperature of $450^{\circ} \mathrm{C}$, you need to put some electrical power. Today, the minimum that can be achieved in thick-film technology is about 220 milliwatts at $450^{\circ} \mathrm{C}$, which is necessary for methane detection. Our goal is to reduce this capacity as much as possible.

One of the options is the work that was carried out with the Italian colleagues (FBK, Trento, Italy) this is the technology of heating up to silicon temperatures. It is a $\mathrm{SiO}_{2} /$ $\mathrm{Si}_{3} \mathrm{~N}_{4}$ silicon substrate, on which a multilayer structure of silicon oxide and silicon nitride is deposited by the CVD method, so that the average stresses in this material are close to zero. A platinum $300 \times 300$ micron microheater is formed on it, either by screen printing or inkjet printing, or by some other method. A sensitive layer is deposited, which is a suspension of nanoparticles of a semiconductor oxide, for example, tin oxide in an organic bond. As a result, a film with a thickness of 5-10 microns is obtained, which has a sensitivity to the target gas, and accordingly, in order to heat up to an operating temperature of $450^{\circ} \mathrm{C}$, it is necessary to enclose a power of the order of 50 milliwatts in continuous mode (maximum annealing temperature in the furnace is $720^{\circ} \mathrm{C}$ ). Naturally, the concentration of methane can not be measured all the time, you can heat it periodically. Accordingly, using all sorts of electronic tricks, you can reduce the power to less than a milliwatt, which is quite acceptable in order to work in wireless networks. The lack of this technology - the sensors should not be much. The largest manufacturer of these sensors, which exists in the world, is the Japanese firm Figaro Engineering Inc. (Osaka), about 12 million pieces per year. To start this silicon technology, the initial investment in it is quite large. In addition, all production is a few dozen silicon wafers. The big disadvantage of silicon is that platinum adheres very badly to silicon oxide. In order to obtain a decent adhesion, an adhesion layer of chromium or titanium or tantalum is applied to the platinum. All these metals, unfortunately, at the operating temperature of the sensor $450^{\circ} \mathrm{C}$ are oxidized. Therefore, platinum exfoliates and the sensor ceases to work.

Several years ago, our competitors appeared on the market - the Japanese firm of Figaro, which now produces silicon MEMSors with the following structure: a microheater suspended on substrates such as legs. It is believed that the membrane structure when heated, and bursts sooner or later. Then when heated, the central part is tucked on these legs and destruction occurs later. Although in general the experiment does not show this.

Another competing firm is the German company Applied Sensor, which is now bought by an Austrian company. Here it is clear that the idea of their Air quality sensor is the same: a microheater on a thin dielectric membrane, a droplet of a gas-sensitive layer is deposited on top, which is tin oxide doped with antimony and a supported palladium catalyst $\left(\mathrm{SnO}_{2} \mathrm{Sb}_{2} \mathrm{O}_{5} /\right.$ Pd).

To deal with all this, we moved on to another substrate material - aluminum oxide, obtained by anodizing the metal.. Platinum, unlike $\mathrm{SiO}_{2} /$ $\mathrm{Si}_{3} \mathrm{~N}_{4}$, adheres well to aluminum oxide, so to produce heaters from platinum there is no need to apply additional adhesion layers, you can simply spray platinum. It can be seen that such a 
heater can be heated to a high temperature, for example, to a temperature of $680^{\circ} \mathrm{C}$.

The goal is to develop a microheater platform without any shortcomings of existing MEMS devices manufactured using silicon technology:

- a comprehensive technology that requires clean rooms that do not match the scale of production of sensors

- incompatibility of materials used in silicon technology $\left(\mathrm{Si}, \mathrm{SiO}_{2} / \mathrm{Si}_{3} \mathrm{~N}_{4}\right.$-membrane, $\mathrm{Pt}$ )

- low efficiency of Pt spraying process and high consumption of precious metal during spraying

- bending of the membrane during temperature cycling, leading to destruction of the microheater.

The mentioned problems of MEMS, in which silicon technology is applied, are the difficulties with adhesion, the high cost of the process. In addition, to spray platinum, spraying is used, which leads to huge unproductive costs of the metal. Therefore it is clear that it is necessary to apply platinum only where it is necessary.

We used those devices that were already mentioned here: Ink-yet Printer Dimatix DMP 2831, which is located in AkKoLab, and the aerosol printing equipment that was in OSTEK, now - in MIPT. If an ink with a viscosity of about 10 centipoise can be used in inkjet printing, then in this installation, when spraying with airflow, an ink with a viscosity of up to 1000 centipoises can be used, i.e. 10 centipoise is ethylene glycol, i.e. from practical point of view 1000 centipoise is glycerol. Accordingly, the jet of aerosol enters the print head, here it is focused by a jet of air and as a result, an aerosol jet containing a solvent and metal particles with a diameter of 10 microns is obtained at the output. The jet retains parallelism at a distance of up to $10 \mathrm{~mm}$. Respectively, can be printed in a non-contact manner, which is important when using thin $\mathrm{Si}_{2} \mathrm{SiO}_{4}$ membranes and ceramic ones. The ink was made in AkKo Lab, based on silver, gold and platinum. We used platinum, platinum particles in them ranging in size from 3 to $8 \mathrm{~nm}$, solvent - ethylene glycol.
These inks are a suspension of platinum particles, they are not granulated, so they can be used in both inkjet and aerosol printing.

As a basis for our sensors, we used two types of materials. These are films of thin 12 micron aluminum oxide, which was obtained by anodic oxidation of an aluminum metal, with an area of $40 \times 60 \mathrm{~mm}$ (thick film technology standard). It is sturdy, it can be put on two supports - it does not collapse under the influence of its own weight. It is easy to process the film, i.e. it is possible to make such structures of a cantilever type, the cat is made understandable for what: it is necessary to heat up to a high temperature the working part of this sensor - the tip of this triangle - so as to obtain the smallest dissipated power. Those heat the working part to a high temperature so that the power spent on it is as low as possible. Therefore, in order to limit the heat sink for this material, a cantilever structure with a heater at the tip of this triangle was used.

The structure of the alumina film has a porous structure, as usual for anodic aluminum; but because the characteristic dimensions of our heaters are units and tens of microns, and the dimensions of these pores are tens and hundreds of $\mathrm{nm}$, this strongly does not hinder us. And at the same time greatly reduces the thermal conductivity of this material in the lateral direction. The thermal conductivity of the film is of the order of $1 \mathrm{~W} / \mathrm{m} \cdot \mathrm{K}$, in contrast to 20 24 for bulk aluminum oxide. This structure was printed here in AkKo Lab. Received a cantilever type heater, with a laser this triangle is cut so as to form a structure with an end portion heated to an operating temperature of $450^{\circ} \mathrm{C}$. The dependence of power on temperature shows that at $450^{\circ} \mathrm{C}$ we consume about 65 milliwatts, which is quite comparable to the power typical for silicon MEMS devices, which have a power of about 50 milliwatts. Therefore, this technology proves to be quite competitive in comparison with the technologies of silicon MEMS.

The same microheater was printed with an aerosol seal. The differences are as follows. For 
Dimatix printer it is difficult to draw smooth curves with a distance between them of the order of 100 microns. In our case, the distance between the lines at the end of the heater is 300 microns. For the Dimatix, a curve with a radius of 100-150 microns is difficult to draw. Aerosol printing allows this, so you can make such a heater. The width of the aerosol line, which is fairly well resolved, is about 40 microns.

The second material that was used to make these microheaters - so-called LTCC, i.e. this is glass ceramics with a sintering temperature of about $850^{\circ} \mathrm{C}$. We ordered thin membranes from this LTCC ceramics, because the ceramic that is commercially available, 100 microns thick, is a very thick, very large heat sink. So a 100 micron ceramic was used, A thin film of the same LTCC ceramics was pressed over the aperture, 30 microns thick. On this membrane - the same structure and the upper material was removed by the laser. The result was a suspended structure in the air, lines 50 microns thick, and a platinum coating thickness of about 1 micron. The thermal characteristics of LTCC ceramics turned out to be worse than aluminum oxide, at a necessary temperature, they had a power of about 150 milliwatts. And it was suspected that the heat dissipation is determined by the thermal conductivity of the ceramic and the thermal conductivity of platinum, and at thicknesses that differ by a factor of 2 , the characteristics were virtually identical. I.e. the main heatsink goes on LTCC ceramics, cheap and convenient for use, although the characteristics are somewhat worse than that of aluminum oxide.

So, the microsensor is an aerosol-drawn platinum ink heater, mounted in the TO-8 casing, the window was cut out with a laser, the entire upper material was removed and a drop of a gas-sensitive standard $\mathrm{SnO}_{2} / \mathrm{Pd}$-tin dioxide doped with palladium was applied to the tip with the same technology. Within 250 milliseconds, the heater reaches the desired temperature of $450^{\circ} \mathrm{C}$. Accordingly, cooling also occurs quickly.
The sensor should only be heated for the duration of measuring the presence of methane. I.e. heat it for 250 milliseconds to $450^{\circ} \mathrm{C}$, measure the response of the sensor, which depends on the concentration of methane and some time to wait. According to GOST (Russian National Standard), it is necessary to carry out measurements at least once every 20 seconds. Accordingly, the duty cycle is of the order of a hundred. And if the power required to heat the operating temperature is 70 milliwatts, then the power can be reduced by a factor of 100 . This already becomes quite acceptable for portable devices such as cell phones, i.e. the average power is less than a milliwatt.

A smart module (smart sensor unit) has also been installed, which has a mounted controller on the board, which controls the heating of this sensor, which measures the resistance of the sensitive layer. All sensors have an inherent drawback - sensitivity to water, to moisture of air. Therefore, on the same board, a humidity sensor is also mounted. It makes it possible to compensate for the departure of the sensor characteristics with varying humidity of the ambient air. All parts of the sensor are modular, they can be removed and calibrated in the laboratory.

The last task is to determine the quality of the gas. In Europe, the gas they buy from us, in winter, when it is cold and the gas consumption increases, it is mixed with nitrogen. As a result, in the gas that enters the kitchen, nitrogen is up to $40 \%$. And under the new law in the European Union it is required to determine not only the gas consumption in cubic meters, but also its quality. The simplest way to determine the quality of a gas is to determine its thermal conductivity. The power required to maintain a constant temperature of the sensor heater is linearly dependent on the methane concentration in the gas mixture $\left(\mathrm{CH}_{4}-\mathrm{N}_{2}\right)$. This is determined by the developed sensor on the LTCC ceramic.

Thus, it is shown that the use of aerosol and inkjet printing on a thin aluminum membrane 
made by anodic oxidation of aluminum foil allows the production of microcircuits compatible with Si MEMS properties.

The combination of thin alumina membranes with additive technology of application of a functional element makes it possible to produce gas sensors with high operating temperature $\left(>600^{\circ} \mathrm{C}\right)$ and process temperature $\left(>1000^{\circ} \mathrm{C}\right)$.

The proposed approach allows to save precious metals used for the formation of functional elements, and allows the manufacture of sensors on relatively simple equipment.

This approach is promising for mediumscale production of sensors. The existing aerosol printer is sufficient to produce $\sim 2000$ chip sensors per hour.

\section{CONCLUSION}

Sergey P. Gubin and speakers in conclusion Albert G. Nasibulin, Irina V. Antonova and Viktor A. Bykov noted the high level and extraordinary usefulness of the carried out seminar. The general opinion of its participants is that the continuation of the seminar is super-urgent.

\section{REFERENCES}

1. Buslaeva EY. Grafenika. Russian Seminar S.P. Gubina (Moscow). Radioelektronika. Nanosistemy. Informatsionnye Tekhnologii (RENSIT), 2011-2017 (in Russ.).

2. Moisala A, Nasibulin AG, Brown DP, Jiang H, Klriachtchev L, Kauppinen EI. Singlewalled carbon nanotube synthesis using ferrocene and iron pentacarbonyl in a laminar flow reactor. Chem.Eng.Sci, 2006, 61(13):4393-4402.

3. Antonova IV, Kotin IA, Kurkina II, Ivanov AI, Yakimchuk EA, Nebogatikova NA, Vdovin VI, Gutakovskii AK, Soots RA. Graphene/Fluorinated Graphene Systems for a Wide Spectrum of Electronics Application. Journal of Material Sciences\& Engineering, 2017, 6(5):1000379. doi: 10.4172/2169-0022.1000379. 